\title{
Spectroscopic studies of Ln(III) complexes with polyoxometalates in solids, and aqueous and non-aqueous solutions
}

\author{
Stefan Lis, ${ }^{1, \dagger}$ Slawomir But, ${ }^{1}$ Andrzej M. Kłonkowski, ${ }^{2}$ and Beata Grobelna ${ }^{2}$ \\ ${ }^{1}$ Faculty of Chemistry, Adam Mickiewicz University, 60-780 Poznań, Poland \\ 2 Department of Chemistry, University of Gdańsk, 80-952 Gdańsk, Poland
}

\begin{abstract}
Chosen polyoxometalate (POM) anions and their lanthanide(III) complexes, LnPOM, have been synthesized and spectroscopically characterized in solid state, aqueous and non-aqueous solutions. POMs, such as Keggin's, Dawson's and Anderson's type, $\mathrm{Na}_{9} \mathrm{EuW}_{10} \mathrm{O}_{36}$, compositions that function as inorganic cryptands $\left(\left[(\mathrm{Na}) \mathrm{P}_{5} \mathrm{~W}_{30} \mathrm{O}_{110}\right]^{14-}\right.$-Preyssler anion, and $\left.\left[(\mathrm{Na}) \mathrm{As}_{4} \mathrm{~W}_{40} \mathrm{O}_{140}\right]^{27-}\right)$, containing inorganic $\left(\mathrm{Na}^{+}, \mathrm{K}^{+}, \mathrm{NH}_{4}^{+}\right.$) or organic (tetrabutylammonium, $\mathrm{NBu}_{4}^{+}$) counter cations were obtained and their $\mathrm{Ln}(\mathrm{III}) \mathrm{com}-$ plexes (sandwiched and encapsulated) studied. The synthesized compounds were identified using elemental and thermogravimetric analysis, UV-Vis spectrophotometry and FTIR spectroscopy. The complexation studies were carried out with the use $\mathrm{Nd}$ (III) and $\mathrm{Er}$ (III) optical absorption and $\mathrm{Eu}$ (III) luminescence spectroscopy. Luminescence characterization, including results of intensity, quantum yields and luminescence lifetimes of EuPOM complexes in aqueous, non-aqueous solutions (DMF, DMSO, acetonitryle) and solid are discussed. Based on luminescence lifetime measurements of the $\mathrm{Eu}(\mathrm{III})$ ion the hydration numbers of its sandwiched (efficient emitters) and encrypted complexes have been determined and quenching effect discussed. The $\mathrm{Eu}(\mathrm{III})$ complexes entrapped in a xerogel matrix have been studied as luminescent materials. Luminescence intensity, lifetime and quantum yield of the EuPOM materials and their photochemical stability, during continuous UV irradiation, were tested.
\end{abstract}

\section{INTRODUCTION}

The majority POMs composed of molybdenum and tungsten polyhedrons, due to their interesting physicochemical properties, and biological importance, have been a subject of numerous studies. This class of compounds has received much attention in the last two decades because of their wide applications in catalysis, material engineering, photochemistry and in medicine. Their attractive and often unusual physicochemical properties are related to their structure, shape, charge density, redox potential, acidic character and solubility. POMs with alkali counter cations such as $\mathrm{Na}^{+}, \mathrm{K}^{+}$and $\mathrm{NH}_{4}^{+}$are well water-soluble compositions. They can be solved in solvents of different polarity, depending on the kind of the counter cation occurring in the POM molecule [1-4]. Generally POMs can be categorized into three structural groups, depending on the coordination number of the heteroatom $[1,2]$. Our previous studies concerned synthesis of POMs and their Ln(III) complexes, representing the three structural groups of POMs and additionally so-called inorganic analogues of crown-ethers and cryptands (e.g. Preyssler's anion). They have been characterized using spectroscopic methods both in aqueous [2,5-8] and non-aqueous solutions [9]. Some of LnPOM complexes show interesting and effective luminescence properties, i.e. high luminescence intensity, its quantum yields

\footnotetext{
† E-mail: blis@amu.edu.pl
}

and long lifetimes of $\operatorname{Ln}(\mathrm{III})$ excited states [10]. Such complete inorganic materials, particularly EuPOM complexes, have been entrapped in xerogel matrices by sol-gel method and examined as luminescent materials. The resulting immobilization of Eu(III) complexes in xerogel matrices is known to enhance emission intensity [11, 12]. These luminescent materials have been also tested for their photochemical stability under continuous UV irradiation.

\section{EXPERIMENTAL}

2.1. Methods. All reagents used in these studies were at least analytical grade, while $\mathrm{Nd}_{2} \mathrm{O}_{3}$ and $\mathrm{Eu}_{2} \mathrm{O}_{3}$ were spectroscopically pure and non-aqueous solvents (DMF, DMSO, acetonitryle, dichloromethane from Fluka) pure for UV spectroscopy (content of $\mathrm{H}_{2} \mathrm{O}<0.005 \%$ ). Elemental analysis of the POMs and their europium complexes were made with the use of an Elemental Analyser 2400 CHN, Perkin Elmer. Thermogravimetric (TG) and differential thermal (DTA) analysis were conducted using a Shimadzu TGA-50H/A50 thermoanalytic system, temperature interval was 293$823 \mathrm{~K}$, heating rate $2 \mathrm{~K} / \mathrm{min}$ in air atmosphere. Absorption spectra were recorded on a UV-2401PC Shimadzu spectrophotometer. The IR spectra were obtained by means of FTIR Bruker JFS 113v spectrophotometer for the samples $(\sim 2 \mathrm{mg})$ prepared in $\mathrm{KBr}$. The corrected luminescence spectra of $\mathrm{Eu}(\mathrm{III})$ were recorded using 
Table 1. The luminescence data of Eu(III) ion in EuPOM complexes in solutions, $\lambda_{\mathrm{exc}}=394 \mathrm{~nm}, \mathrm{C}_{\mathrm{Eu}(\mathrm{III})}=0.001 \mathrm{~mol} / \mathrm{l}$.

\begin{tabular}{|c|c|c|c|c|}
\hline Compound & $\begin{array}{l}\text { Lifetime } \\
{[\mathrm{ms}]}\end{array}$ & Hydration number & $\begin{array}{l}\text { Luminescence Intensity [a.u.], } \\
\qquad \lambda_{\max }=615 \mathrm{~nm}\end{array}$ & Quantum yield \\
\hline$\overline{\mathrm{Eu}\left(\mathrm{ClO}_{4}\right)_{3}}$ & 0.11 & 9.3 & 0.01 & $2.60 \times 10^{-3}$ \\
\hline $\mathrm{Na}_{9}\left[\mathrm{EuW}_{10} \mathrm{O}_{36}\right]$ & 2.29 & 0.2 & $2.0^{\mathrm{c}}$ & $4.19 \times 10^{-3}$ \\
\hline $\mathrm{K}_{17}\left[\mathrm{Eu}\left(\mathrm{P}_{2} \mathrm{~W}_{17} \mathrm{O}_{61}\right)_{2}\right]$ & 3.08 & 0.1 & 0.4 & $1.38 \times 10^{-2}$ \\
\hline $\mathrm{Eu}_{2} \mathrm{TeMo}_{6} \mathrm{O}_{24}$ & 0.19 & 5.1 & 0.08 & - \\
\hline $\mathrm{K}_{25}\left[(\mathrm{Eu}) \mathrm{As}_{4} \mathrm{~W}_{40} \mathrm{O}_{140}\right]$ & 0.25 & 3.7 & $0.02^{\mathrm{d}}$ & $9.06 \times 10^{-3}$ \\
\hline $\mathrm{K}_{12}\left[(\mathrm{Eu}) \mathrm{P}_{5} \mathrm{~W}_{30} \mathrm{O}_{110}\right]$ & 0.30 & 3.1 & $0.23^{\mathrm{e}}$ & $9.6 \times 10^{-5}$ \\
\hline$\left(\mathrm{NBu}_{4}\right)_{12}\left[(\mathrm{Eu}) \mathrm{P}_{5} \mathrm{~W}_{30} \mathrm{O}_{110}\right]^{\mathrm{a}}$ & 0.79 & 0.6 & $0.37^{\mathrm{e}}$ & $1.1 \times 10^{-4}$ \\
\hline$\left(\mathrm{NBu}_{4}\right)_{8} \mathrm{H}_{3}\left[\mathrm{Eu}\left(\mathrm{PMo}_{2} \mathrm{~W}_{9} \mathrm{O}_{39}\right)_{2}\right]^{\mathrm{b}}$ & 1.11 & 0.2 & $0.95^{\mathrm{f}}$ & - \\
\hline \multirow{2}{*}{$\mathrm{K}_{11,13}\left[\mathrm{Eu}\left((\mathrm{P} / \mathrm{Si}) \mathrm{Mo}_{\mathrm{x}} \mathrm{W}_{11-\mathrm{x}} \mathrm{O}_{39}\right)_{2}\right]$} & $1.2-3.5$ & 0.1 & $0.0-4.8$ & $10^{-4}-10^{-2}$ \\
\hline & Ref. [6] & & Ref. [6] & Ref. [18] \\
\hline
\end{tabular}

${ }^{\mathrm{a}}$ in acetonitryle, ${ }^{\mathrm{b}}$ in DMF, ${ }^{\mathrm{c}} \lambda_{\max }=300 \mathrm{~nm},{ }^{\mathrm{d}} \mathrm{C}_{\mathrm{Eu}(\mathrm{III})}=1 \times 10^{-4} \mathrm{~mol} / \mathrm{l},{ }^{\mathrm{e}} \mathrm{C}_{\mathrm{Eu}(\mathrm{III})}=1 \times 10^{-2} \mathrm{~mol} / \mathrm{l},{ }^{\mathrm{f})} \lambda_{\mathrm{exc}}=342 \mathrm{~nm}$.

Table 2. The luminescence characterization of EuPOM complexes entrapped to xerogels.

\begin{tabular}{lcccc}
\hline HPAS & Type of matrix & $\begin{array}{c}\text { Lifetime }[\mu \mathrm{s}], \\
\lambda_{\text {exc }}=394 \mathrm{~nm}\end{array}$ & $\begin{array}{c}\text { Luminescence Intensity [a.u.], } \\
\lambda_{\max }=615 \mathrm{~nm}\end{array}$ & Quantum yield \\
\hline $\mathrm{Na}_{9} \mathrm{EuW}_{10} \mathrm{O}_{36}$ & $\mathrm{SiO}_{2}$ & 642.8 & $23.7^{*}$ & 0.123 \\
& $\mathrm{SiO}_{2}-\mathrm{PDMS}$ & 491.9 & $19.8^{*}$ & 0.104 \\
& $\mathrm{SiO}_{2}-\mathrm{TEG}$ & 508.4 & $24.4^{*}$ & 0.066 \\
\hline $\mathrm{Eu}_{2} \mathrm{TeMo}_{6} \mathrm{O}_{24}$ & $\mathrm{SiO}_{2}$ & 245.9 & $15.3^{+}$ & 0.027 \\
& $\mathrm{SiO}_{2}-\mathrm{PDMS}$ & 162.9 & $23.8^{++}$ & 0.018 \\
& $\mathrm{SiO}_{2}-\mathrm{TEG}$ & 275.4 & $37.6^{++}$ & 0.012 \\
\hline
\end{tabular}

${ }^{*} \lambda_{\mathrm{exc}}=394 \mathrm{~nm},{ }^{+} \lambda_{\mathrm{exc}}=320 \mathrm{~nm},{ }^{++} \lambda_{\mathrm{exc}}=315 \mathrm{~nm},{ }^{+++} \lambda_{\mathrm{exc}}=330 \mathrm{~nm}$.

a Perkin-Elmer MPF-3 spectrofluorimeter. The luminescence lifetime of $\mathrm{Eu}(\mathrm{III})$ was measured with the use of the detection system described earlier, consisting of a nitrogen laser (KB6211) and a tunable dye laser [13]. The luminescence decay curves observed in this work were analyzed by a single exponential fitting, providing the decay constants. The luminescence quantum yield, $\Phi$, of the $\mathrm{Eu}(\mathrm{III})$ ion in solution was calculated using $\left[\mathrm{Ru}(\mathrm{bpy})_{3}\right] \mathrm{Cl}_{2}$ as a standard. In the case of powder samples $\Phi$ was determined based on the procedure described by Wrighton et al. [14]. Measurement of luminescence quantum yields of the powder samples involved determination of the diffuse reflectance of the sample relative to a nonabsorbing standard $(\mathrm{KBr})$ at the excitation length, and then measuring the emission of the sample under the same conditions [15]. The quantum yield is the ratio of the emitted photons to the difference in the number of diffuse reflected photons from the sample and the nonabsorbing standard, has been calculated using the equation (1):

$$
\Phi=\frac{E}{R_{\text {std }}-R_{\text {smpl }}}
$$

where $E$ is the area of the corrected emission curve of the sample, $R_{\text {std }}$ and $R_{\text {smpl }}$ are corrected areas under the diffuse reflectance curves of the nonabsorbing standard and samples, respectively, at the excitation wavelength. The calculated values of the luminescence quantum yields of the samples studied are given in Tables 1 and 2.

The Eu(III) complexes entrapped in xerogels were irradiated by means of a UV lamp of radiation power $0.53 \mathrm{~W} / \mathrm{cm}^{2}$.

\subsection{Synthesis and identification of compounds.}

The lacunary structures of the heteropolyanions (for example $\mathrm{SiW}_{11} \mathrm{O}_{39}^{8-}$ ) were obtained from the corresponding plenary structures $\left(\mathrm{SiW}_{12} \mathrm{O}_{40}^{4-}\right)$ as a result of their partial degradation as described earlier [16]. Europium sandwiched complexes $\mathrm{Eu}(\mathrm{POM})_{2}$ were obtained according to the method described by Peacock and Weakley [17] and modified by us [18]. The cryptand analogues of the heteropolyanions and their Eu(III)-encrypted derivatives were prepared as previously described $[5,15,19,20]$. Tetrabutylammonium salts of the chosen compounds was obtained with using a literature procedure [21]. Identification of synthesized compounds was done by comparison of the IR spectra of obtained compounds with those previously reported, elemental and thermogravimetric analysis $[5-7,18]$ and our own spectrophotometric method for determination of tungsten and molybdenum contents. The spectrophotometric method enables the simultaneous determination of $\mathrm{W}(\mathrm{VI})$ and $\mathrm{Mo}(\mathrm{VI})$ in 
POMs and their Ln/POM complexes with disodium-1,2dihydrobenzene-3,5-disulfate (Tiron), used as colorimetric reagent [22].

\subsection{Synthesis of the POMs entrapped in sol-gel} matrices. A wet gel product was obtained after some days by sol-gel process (hydrolysis and polycondensation) of tetramethoxysilane (TMOS) in mixture with methanol and aqueous solution of EuPOM complex [23]. Methylated silicate xerogels was synthesized in the similar way. A $1: 1$ mixture of TMOS (Aldrich) and polydimethylsiloxane (PDMS 200, Aldrich)) was dissolved in methanol and water as reagent was added [24]. In the case of TMOS and triethylenglycol (TEG) with $1: 1$ molar ratio, the components were dissolved in methanol, heated to $60^{\circ} \mathrm{C}$ and stirred for ten minutes [25]. Then aqueous solution of EuPOM complex was added. In each gel preparation the molar ratio [alkoxidegroup] : $\left[\mathrm{H}_{2} \mathrm{O}\right]=1: 1$ and the resulting wet gels were dried at room temperature to obtain xerogels. The final concentration of the Eu(III) complexes in xerogels are $5 \times 10^{-5} \mathrm{~mol} / \mathrm{g}$ xerogel.

\section{RESULTS AND DISCUSSION}

The compositions of POMs were determined based on results of the elemental $(\mathrm{C}, \mathrm{N}, \mathrm{H})$, thermogravimetric analysis $\left(\mathrm{H}_{2} \mathrm{O},\left[\mathrm{NH}_{4}\right]^{+},\left[\mathrm{NBu}_{4}\right]^{+}, \mathrm{H}^{+}\right)$, spectrophotometric determinations of Mo and $\mathrm{W}$ in the range of $\mathrm{UV}-\mathrm{Vis}$, and FTIR spectra analysis. The elemental analysis was very useful in the case of POM compositions containing an organic counter cation.

The use of the FTIR spectroscopy has shown to be a very useful tool in studies of POMs and their complexes due to easy indication of the plenary, lacunary and of sandwich complexes, based on characteristic features of the spectra [6]. The formation of the lacunary structure ( $\mathrm{pH}$ dependent degradation of an appropriate plenary structure) indicates a split of the P-Oa and W-Oc-W band oscillations, as a consequence of existence of two different coordination environments of phosphorus and oxygen atoms, Oc. FTIR spectroscopy has been used to fingerprint the POM structures because of good correlations between spectral peak positions, shapes, and relative intensities of the spectra, obtained for solid and solution. These correlations strongly indicate identical structures [18]. The FTIR spectra of tetrabutylammonium compositions of POMs have generally the same bands as the spectra recorded for the potassium or ammonium salts. Additional bands attributed to the $\mathrm{C}-\mathrm{H}$ and $\mathrm{C}-\mathrm{C}$ oscillations of the $\left(\mathrm{NBu}_{4}\right)^{+}$organic species, in the range of $1300-1500 \mathrm{~cm}^{-1}$ and $2800-3000 \mathrm{~cm}^{-1}$, occur in this case.

Absorption spectra of $\mathrm{Nd}(\mathrm{III})$ and $\mathrm{Er}(\mathrm{III})$ in the range of their hypersensitive transitions ${ }^{4} \mathrm{I}_{9 / 2} \rightarrow{ }^{2} \mathrm{H}_{9 / 2}$ and ${ }^{4} \mathrm{I}_{15 / 2} \rightarrow{ }^{2} \mathrm{H}_{11 / 2}$, respectively, were measured for various metal:ligand ratios in non-aqueous solutions. Positions and intensities of the spectra are sensitive to the ligand field of POMs and can be used to evaluate the formation of LnPOM complexes. Examples of the spectra, measured for various $\mathrm{Ln}(\mathrm{III})$ : POM molar ratios, ranging from $1: 0$ to $1: 3$, in DMSO and DMF solutions, are presented in Figures 1 and 2.

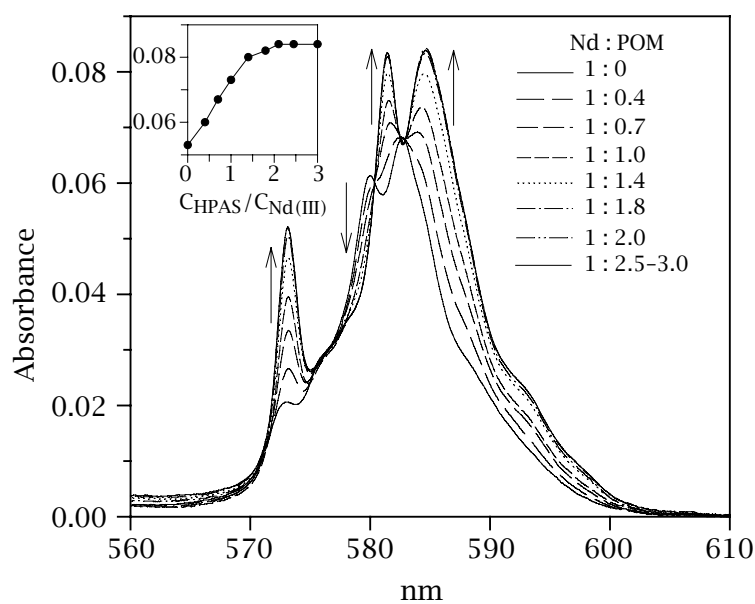

Figure 1. Absorption spectra of $\mathrm{Nd}(\mathrm{III})$ in the range of the hypersensitive transition $\left({ }^{4} \mathrm{I}_{9 / 2} \rightarrow{ }^{2} \mathrm{H}_{9 / 2}\right)$ for various $\mathrm{Nd}:\left[\mathrm{NBu}_{4}\right]_{6} \mathrm{H}\left[\mathrm{PMo}_{2} \mathrm{~W}_{9} \mathrm{O}_{39}\right]$ molar ratios in DMSO, $\mathrm{C}_{\mathrm{Er}(\mathrm{III})}=0.001 \mathrm{~mol} / \mathrm{l}$.

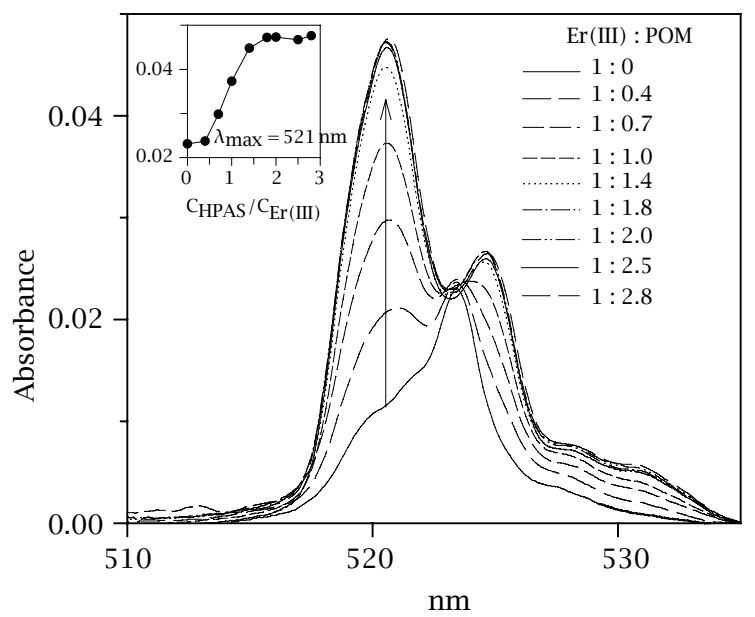

Figure 2. Absorption spectra of $\operatorname{Er}(\mathrm{III})$ in the range of the hypersensitive transition $\left({ }^{4} \mathrm{I}_{15 / 2} \rightarrow{ }^{2} \mathrm{H}_{11 / 2}\right)$ for various $\mathrm{Er}:\left[\mathrm{NBu}_{4}\right]_{6} \mathrm{H}\left[\mathrm{PMo}_{2} \mathrm{~W}_{9} \mathrm{O}_{39}\right]$ molar ratios in DMF, $\mathrm{C}_{\mathrm{Er}(\mathrm{III})}=0.001 \mathrm{~mol} / \mathrm{l}$.

These spectra show an increase in absorption and a shift of their maxima consistent with formation of $\mathrm{ML}_{2}$ complexes.

Recently, based on the analyses of the absorption spectra of $\mathrm{Nd}(\mathrm{III})$ and $\mathrm{Er}(\mathrm{III})$ ions, we evidenced formation of the ML and $\mathrm{ML}_{2}$ complexes with Keggin's and Dawson's type of polyanions [7, 18, 26] and ML complexes with the polyanion $\left[(\mathrm{Na}) \mathrm{As}_{4} \mathrm{~W}_{40} \mathrm{O}_{140}\right]^{27-}$ [18] in aqueous solutions. In the case of $\left[\mathrm{MnMo}_{9} \mathrm{O}_{32}\right]^{6-}$ 
(Anderson's anion) with the $\mathrm{Nd}(\mathrm{III})$ ion spectroscopic studies demonstrated that the $\mathrm{M}_{2} \mathrm{~L}$ type of complexes occur in solution [7].

Formation of the $\mathrm{ML}_{2}$ sandwiched complexes in non-aqueous solvents (DMSO, DMF, acetonitryle) as are shown in Figures 1 and 2. They were also earlier observed in aqueous solutions [7, 26]. Our studies concerning chemometrics and factor analysis of the $\mathrm{Nd}$ (III) absorption spectra with chosen POM complexes confirmed formation of the $\mathrm{M}_{2} \mathrm{~L}, \mathrm{ML}, \mathrm{ML}_{2}$ complexes [26, 27]. In spectrophotometric studies we also proved that formation of LnPOM complexes is function of ionic strength. For example, in equimolar solutions of $\mathrm{Nd}$ (III) and Keggin's POM of high ionic strength, a preferential formation of the sandwich complexes $\mathrm{Nd}(\mathrm{HPAS})_{2}$, instead of NdHPAS, were observed [6, 7].

$\mathrm{Eu}(\mathrm{III})$ luminescence studies (intensity, lifetime measurements and quantum yield) of the EuPOM systems were used to investigate their emission properties, effectiveness of energy transfer processes, hydration numbers and complex compositions [6, 7].

The Eu(III) luminescence lifetimes measured for the $\mathrm{Eu} / \mathrm{POM}$ complexes were used to calculate the number of water molecules present in the inner sphere of the $\mathrm{Eu}(\mathrm{III})$ ion, using the following eq. [28]:

$$
n_{\mathrm{H}_{2} \mathrm{O}}=1.05 \tau_{\mathrm{H}_{2} \mathrm{O}}^{-1}-0.7
$$

The lifetime of $\mathrm{Eu}(\mathrm{III})$ excited state is efficiently quenched by $\mathrm{OH}$ oscillators of inner sphere $\mathrm{H}_{2} \mathrm{O}$ molecules bound to the Eu(III) ion. Based on the Eu(III) luminescence lifetime measured for EuPOM complexes in non-aqueous solutions and solid the hydration numbers of this ion were calculated as shown in Table 1 and compared with those obtained earlier in aqueous solution [5-7]. The measured Eu(III) luminescence lifetime gave the longest values for sandwiched complexes with inorganic counter cations in aqueous solution (from 1.2 to $3.5 \mathrm{~ms}$ ) and with organic counter cation $(1.11 \mathrm{~ms})$ in DMF solution. The hydration numbers calculated from the measured lifetime values indicate no water molecules in the $\mathrm{Eu}(\mathrm{III})$ inner coordination sphere of the complexes. In the case of Eu(III) encapsulated Preyssler's complexes, the composition with organic counter ion $\left(\mathrm{NBu}_{4}\right)_{12}\left[(\mathrm{Eu}) \mathrm{P}_{5} \mathrm{~W}_{30} \mathrm{O}_{110}\right]$ has smaller hydration number $(\sim 0.5)$ than that with inorganic counter ion $\mathrm{K}_{12}\left[(\mathrm{Eu}) \mathrm{P}_{5} \mathrm{~W}_{30} \mathrm{O}_{110}\right]$ having 3 waters of hydration. It is worth to mention that the solid Eu(III) complexes have coordination number of 8 or 9 in the case of solution.

Examples of the luminescence excitation and emission spectra of Eu/POM complexes recorded in nonaqueous solvents are presented in Figure 3.

The Eu(III) luminescence lifetimes obtained for $\mathrm{Eu} / \mathrm{POMs}$ in non-aqueous solvents with various molar ratios of the components demonstrated the $\mathrm{ML}_{2}$ complex formation (see Figure 4).

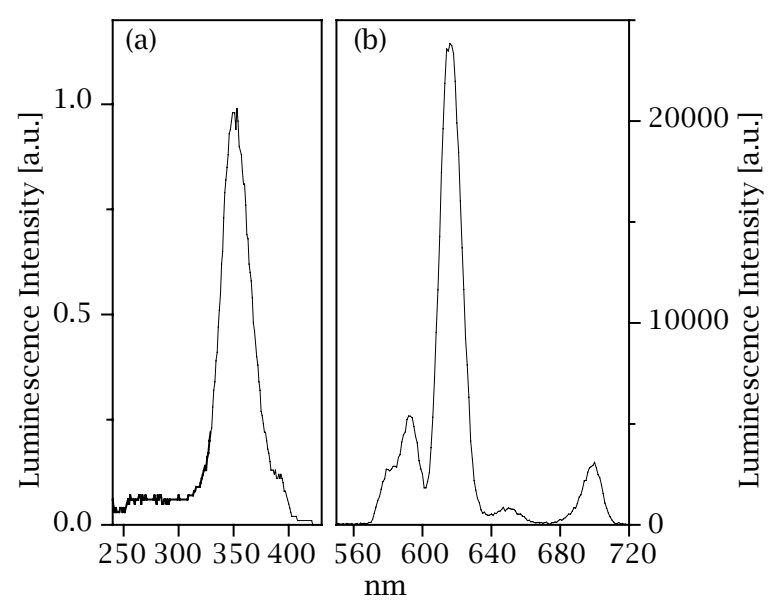

Figure 3. Luminescence excitation (a) and emission (b) spectra of $\mathrm{Eu}(\mathrm{III})$ in $\left(\mathrm{NBu}_{4}\right)_{8} \mathrm{H}_{3}\left[\mathrm{Eu}\left(\mathrm{PMo}_{2} \mathrm{~W}_{9} \mathrm{O}_{39}\right)_{2}\right]$ in DMF.

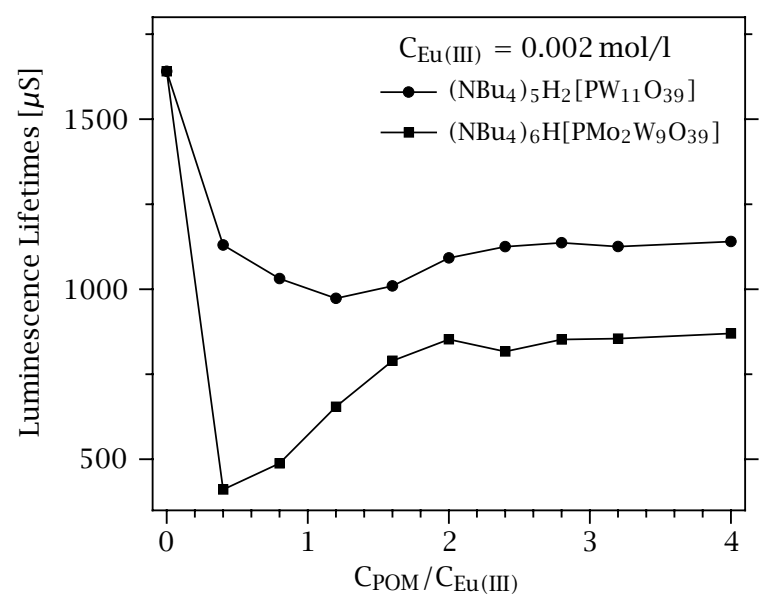

Figure 4. Eu(III) luminescence lifetime as a function of the POM : Eu(III) molar ratios in non-aqueous solvent (DMF).

The luminescence spectra of non-aqueous solutions are generally similar to those obtained in aqueous solution [6]. Excitation spectra of the Eu(III) molibdotungstate compounds show strong emission band $\left(\lambda_{\max } \sim 340 \mathrm{~nm}\right)$ due to ligand to metal energy transfer (LMET) from the tungstate group to the Eu(III) ion [29, 30].

Our previous studies have shown that the most intense $\mathrm{Eu}(\mathrm{III})$ luminescence was observed for the $\left(\mathrm{EuW}_{10} \mathrm{O}_{36}\right)^{9-}$ and $\left[\mathrm{Eu}\left(\mathrm{SiMoW}_{10} \mathrm{O}_{39}\right)_{2}\right]^{13-}$ sandwiched complexes due to energy transfer from the tungstate group to the $\mathrm{Eu}(\mathrm{III})$ ion. In the case of $\left[\mathrm{Eu}\left(\mathrm{SiW}_{11} \mathrm{O}_{39}\right)_{2}\right]^{13-}$ and $\left[\mathrm{Eu}\left(\mathrm{P}_{2} \mathrm{~W}_{17} \mathrm{O}_{61}\right)_{2}\right]^{17-}$ and the Eu-encrypted complexes a weak luminescence intensity was observed. In latter cases the transfer from ligand to Eu(III) does not occur. Interesting pattern of the Eu(III) luminescence lifetime and quantum yield were observed in the case of the heterotungstomolybdate Eu-sandwiched complexes $\left\{\left[\mathrm{Eu}\left(\mathrm{Si}(\mathrm{P}) \mathrm{Mo}_{x} \mathrm{~W}_{11-x} \mathrm{O}_{3} 9\right)_{2}\right]^{13-}\right\}$. A linear dependence 


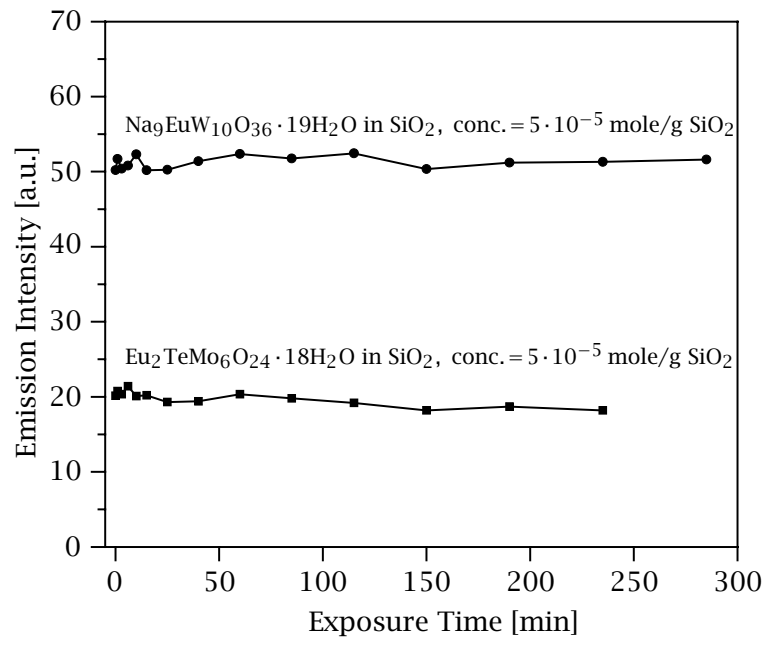

Figure 5. The photochemical stability of EuPOMs complexes.

of the $\mathrm{Eu}(\mathrm{III})$ luminescence lifetime, $\tau$, and quantum yield, $\phi$, on the content of Mo (number of atoms $\mathrm{x}$, where $x=0-9)$ in the $\left[\mathrm{Eu}\left(\mathrm{Si}(\mathrm{P}) \mathrm{Mo}_{x} \mathrm{~W}_{11-x} \mathrm{O}_{39}\right)_{2}\right]^{13-}$ structures were observed. These dependences can be applied for the determination contents of Mo in polytungstomolybdate complexes [6, 9, 18].

Based on luminescence lifetimes measured both for solid and aqueous solutions, we found no $\mathrm{H}_{2} \mathrm{O}$ in $\mathrm{Eu}$ (III) inner sphere in the sandwiched complexes $\mathrm{Eu}(\mathrm{POM})_{2}$. Whereas the complexes $\mathrm{Eu}_{2} \mathrm{POM}$ have four or six water molecules and europium-encrypted derivatives possess three or four $\mathrm{H}_{2} \mathrm{O}$ 's in the $\mathrm{Eu}(\mathrm{III})$ inner coordination sphere.

In order to increase photochemical stability and to minimise water $(\mathrm{O}-\mathrm{H}$ oscillators) interaction, we used $\mathrm{Eu}(\mathrm{III})$ complexes with the heteropolyanions $\left(\mathrm{Na}_{9} \mathrm{EuW}_{10} \mathrm{O}_{36}, \mathrm{Eu}_{2} \mathrm{TeMo}_{6} \mathrm{O}_{24}\right)$ entrapped in silica xerogel matrix. The luminescence characterization of EuPOM complexes entrapped to xerogels are presented in Table 2. The resulting encapsulation and immobilization of Eu(III) complexes with POMs in xerogel matrices enhanced emission intensities and luminescence quantum yield related to solid EuPOM and EuPOM dissolved in the solutions.

The Eu(III) complexes entrapped in xerogels were tested for their photochemical stability during UV irradiation. As it is shown in Figure 5, the emission intensity (at $\lambda_{\max }=617 \mathrm{~nm}$, when $\lambda_{\text {exc }}=273 \mathrm{~nm}$ ) of the silica xerogel doped with $\mathrm{Eu}$ (III) complexes during UV irradiation remains constant within experimental error. Thus, for the $\mathrm{Eu}(\mathrm{III})$ in inorganic environment there is present no photodegradation effect due to relative high energy (UV) quanta used for the irradiation.

\section{ACKNOWLEDGEMENT}

This work was supported by the Polish State Committee for Scientific Research, Grant No. 4 T08A 04423.

\section{REFERENCES}

[1] M. T. Pope, Heteropoly and Isopolyoxometalates, Springer-Verlag, New York 1983.

[2] S. Lis, Acta Phys. Pol. A 90 (1996), 275.

[3] D. E. Katsoulis, Chem. Rev. 98 (1998), 359.

[4] M. T. Pope and A. Müler, Angew. Chem. Int. Ed. Engl. 30 (1991), 34.

[5] S. Lis, M. Elbanowski, and S. But, Acta Phys. Pol. A 90 (1996), 361.

[6] S. Lis and S. But, Materials Science Forum 315-317 (1999), 431.

[7] S. Lis and S. But, J. Alloys Comp. 300-301 (2000), 370.

[8] A. Szyczewski, S. Lis, Z. Kruczynski, and S. But, J. Alloys Compd. 341 (2002), 307.

[9] S. But, Ph.D. Thesis, Adam Mickiewicz University, Poznan, Poland, 1999.

[10] R. Ballardini, E. Chiorboli, and V. Balzani, Inorg. Chim. Acta 95 (1984), 323.

[11] O. A. Serra, E. J. Nassar, G. Zapparolli, and I. L. V. Rosa, J. Alloys Compd. 207-208 (1994), 454.

[12] V. Bekieri, G. Pistolis, and P. Lianos, J. Non. Cryst. Solids 226 (1998), 200.

[13] Z. Stryla, S. Lis, and M. Elbanowski, Optica Applicata XXIII (1993), 163.

[14] M. S. Wrighton, D. S. Ginley, and D. L. Morse, J. Phys. Chem. 78 (1974), 2229.

[15] A. M. Klonkowski, S. Lis, M. Pietraszkiewicz, Z. Hnatejko, K. Czarnobaj, and M. Elbanowski, Chem. Mater. 15 (2003), 656.

[16] Y. Jeannin and J. Martin-Frere, Inorg. Synth. 27 (1990), 71.

[17] R. D. Peacock and T. J. R. Weakley, J. Chem. Soc. A (1971), 1836.

[18] S. Lis and S. But, J. Inclusion Phenom. Molec. Recognition Chem. 35 (1999), 225.

[19] I. Creaser, M. C. Heckel, R. J. Neitz, and M. T. Pope, Inorg. Chem. 32 (1993), 1573.

[20] M. R. Antonio and L. Soderholm, Inorg. Chem. 33 (1994), 5988.

[21] J. Bartis, S. Sukal, M. Dankova, E. Kraft, R. Kronzon, M. Blumenstein, and L. C. Francesconi, J. Chem. Soc., Dalton Trans. 11 (1997), 1937.

[22] S. Lis and S. But, J. Alloys Compds. 303-304 (2000), 132.

[23] K. Czarnobaj, M. Elbanowski, Z. Hnatejko, A. M. Klonkowski, S. Lis, and M. Pietraszkiewicz, Spectrochim. Acta A 54 (1998), 2183.

[24] Z. Hnatejko, A. M. Klonkowski, S. Lis, K. Czarnobaj, M. Pietraszkiewicz, and M. Elbanowski, Mol. Cryst. Liq. Cryst A. 354 (2000), 207.

[25] P. Judeinstein and H. Schmidt, J. Sol-Gel Sci. Tech. 3 (1994), 189.

[26] G. Meinrath, S. Lis, S. But, and M. Elbanowski, Talanta 55 (2001), 371. 
[27] G. Meinrath and S. Lis, Fresenius, J. Anal. Chem. 369 (2001), 124.

[28] P. P. Barthelemey and G. R. Choppin, Inorg. Chem. 23 (1989), 2044.
[29] G. Blasse, G. J. Dirksen, and F. Zonnevijlle, J. Inorg., Nucl. Chem. 41 (1981), 2947.

[30] G. Blasse, Eur. J. Solid State Inorg. Chem. 28 (1991), 719. 


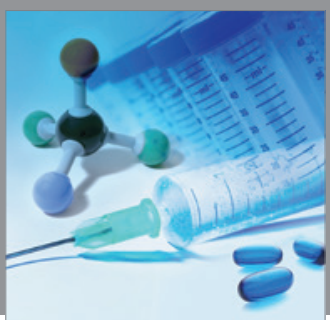

International Journal of

Medicinal Chemistry

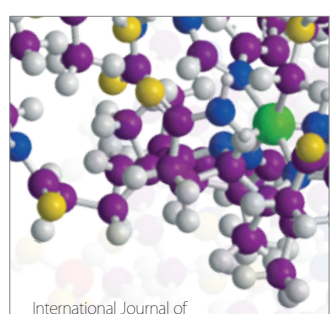

Carbohydrate Chemistry

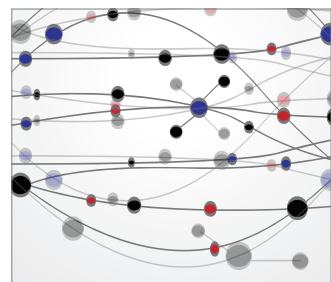

The Scientific World Journal
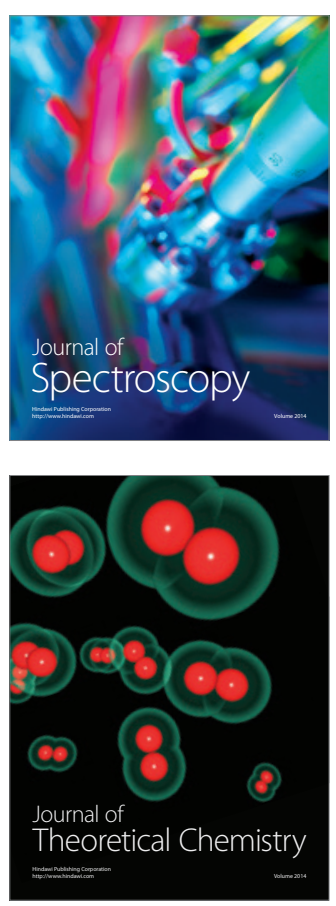
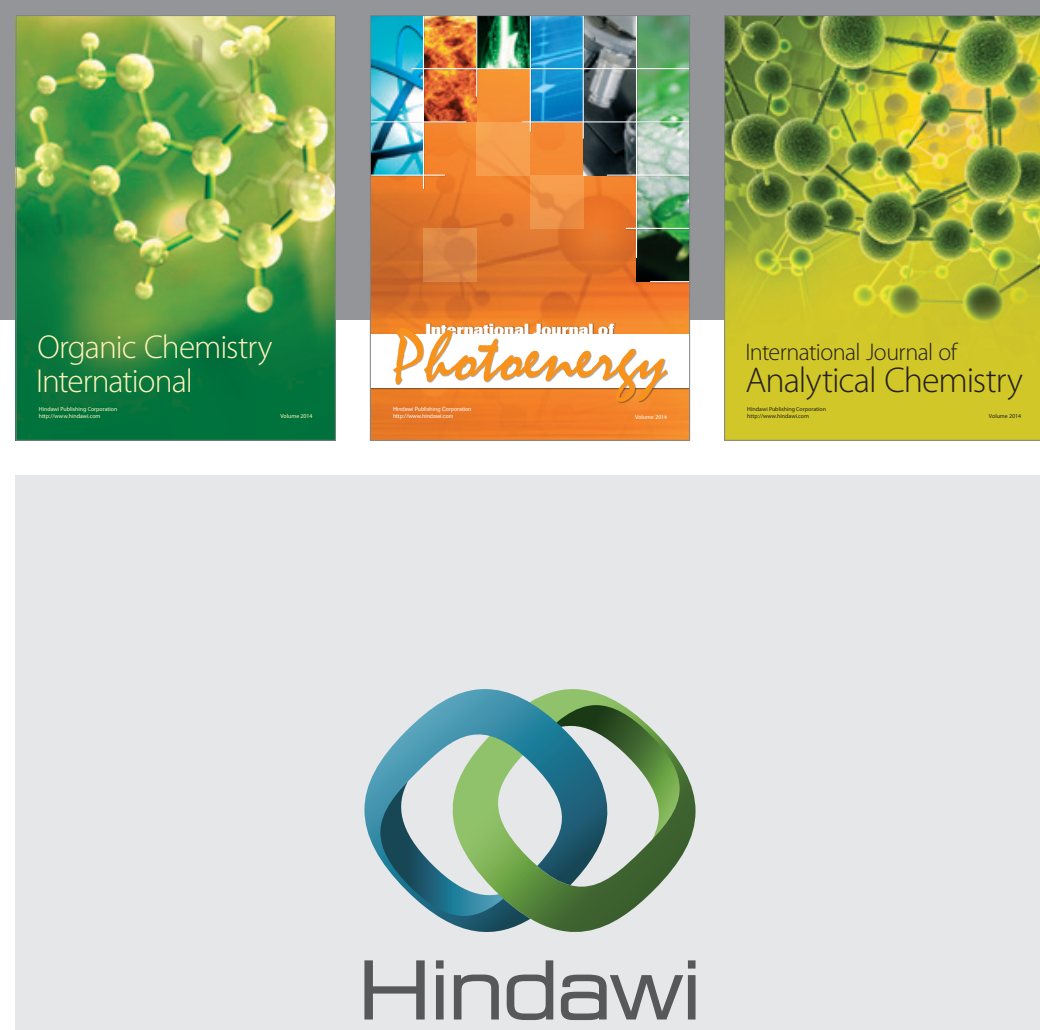

Submit your manuscripts at

http://www.hindawi.com
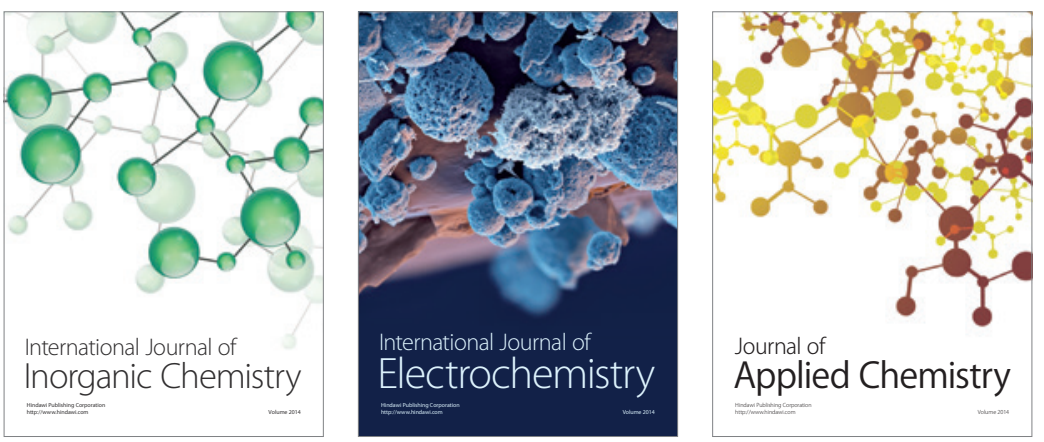

Journal of

Applied Chemistry
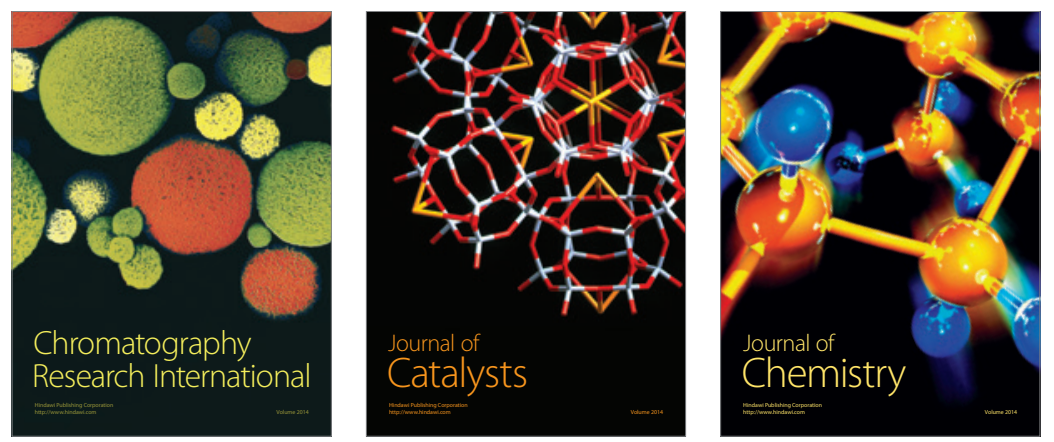
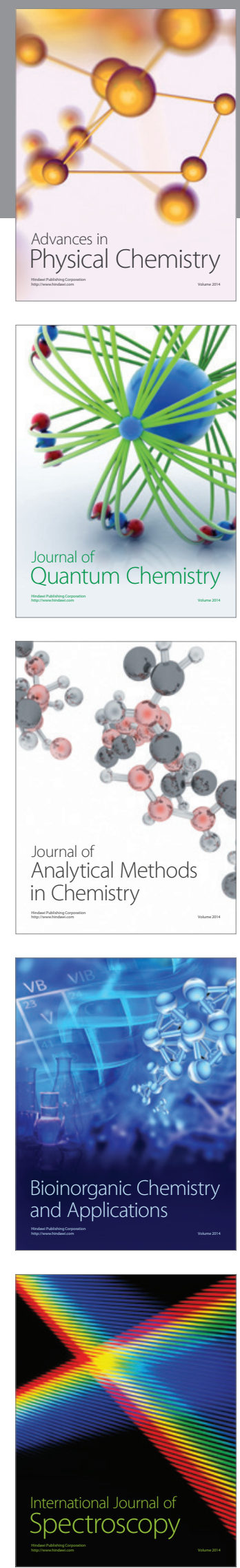